REVIEW

\title{
A Review of the Largest Online Teaching in China for Elementary and Middle School Students during the COVID-19 Pandemic
}

\author{
Longjun Zhou, ${ }^{1,2}$ Fangmei Li ${ }^{3}$
}

1. Jiangsu Second Normal University, Nanjing 211200, Jiangsu, China

2. Engineering Research Center of Digital Learning Support Technology, Ministry of Education, Changchun 130000, Jilin, China

3. Nanjing Dianji Institute of Psychological Education, Nanjing 210000, Jiangsu, China

\begin{abstract}
In order to reduce the impact of COVID-19 Pandemic on teaching, online teaching with the goal of "School is Out, but Class is On" was launched throughout China, and had achieved the "School is Out, but Class is On" of more than 200 million people. This special period of education has attracted great attention from Chinese scholars, and has conducted research on the theme of online teaching during the pandemic. Based on the relevant data of CNKI and other foreign open databases, this article reviewed and summarized the relevant researches of COVID-19 pandemic online teaching by survey and analysis. Through the statistical analysis of related research, the current research on online teaching mainly focuses on the selection of online teaching platforms and resources, the overview of online teaching organization, the implementation and the evaluation of problems.
\end{abstract}

Best Evid Chin Edu 2020; 5(1):549-567.

Doi: 10.15354/bece.20.re040.

Keywords: COVID-19; "School is Out, but Class is On"; Chinese Elementary and Middle School; Online Teaching

\footnotetext{
About the Author: Fangmei Li, Nanjing Dianji Institute of Psychological Education, Nanjing 210000, Jiangsu, China.Email:1037576462@qq.com;

Correspondence to: Longjun Zhou, Professor, Jiangsu Second Normal University, Nanjing 211200, Jiangsu; and Research Scientist, Engineering Research Center of Digital Learning Support Technology, Ministry of Education, Changchun 130000, Jilin, China. Email: 294437034@qq.com.
}

Conflict of Interests: None. 


\section{Background}

OVID-19 has engulfed most countries and regions in the world. According to the statistics of the World Health Organization (WHO), as of April 20, 2020, 211 countries and regions have reported confirmed cases, and the cumulative number of confirmed cases has reached more than 2.3 million (WHO, 2020). Affected by COVID-19 pandemic, a record number of students worldwide cannot continue their normal school life. According to the monitoring of the United Nations Educational, Scientific and Cultural Organization (UNESCO), as of April 20, Beijing time, 191 countries have implemented nationwide school suspensions, affecting approximately 1.575 billion students which accounting for $91.3 \%$ of the total number of registered students worldwide (UNESCO Institute for Statistics, 2020).

Because of it, countries began to seek respond ways actively to minimize the impact of the pandemic on education. Among them, online teaching has become an important measure for many countries to learn during the school suspension. They had deployed distance education and tried to solve its complexity to promote the "Class is On" during the COVID-19 pandemic. In this process, from elementary, middle school to college, from Europe, Asia to North America, all countries affected by the pandemic have become large-scale experimental sites for online teaching.

The Chinese government launched "School is Out, but Class is On", integrating all teaching resources, using the Internet and informatization technology, implementing distance learning and home learning for over 200 million students during the delayed spring semester period, which greatly guarantees the continuity of learning during the pandemic (Ding \& Yu, 2020).

With the continuous spread of the pandemic, the global school suspension has become server. Many countries and education researchers pay attention to how China conducts online teaching during the pandemic, and it has become a hotspot in the fields of education management, information technology, policy science and decision-making consulting around the world.

Based on this, the research on Chinese online teaching during COVID-19 pandemic needs to be analyzed and reviewed. So that to further summarize the hotspots, difficulties and the existing problems during the pandemic, and to reflect on the weak points in order to conduct a more in-depth study. This review is based on the published data from CNKI, foreign open databases, and relevant official websites of China. It combined with relevant research reports, and provides a reference for the current implementation of global online teaching.

\section{Literature Retrieval}

This article reviewed and summarized the relevant researches of COVID-19 pandemic online teaching by survey and analysis.

We conducted research on the CNKI database and foreign open databases represented by SSRN, use "School is Out, but Class is On", "COVID-19", and "Online 
Teaching" as keywords to search public information on other related websites. After screening irrelevant documents, as of April 18, 2020, a total of 156 articles were obtained (103 from CNKI, 42 from foreign open database, and 11 from other valid documents), of which there are 105 articles related to "elementary and middle school". After reviewed and analyzed these 156 articles, we found that the research on online teaching has developed rapidly and continuously.

As far as research objects, they include national or local education departments, college education researchers, elementary and middle school teachers, and social education researchers. Among them, college educators, elementary and middle school teachers are the major.

As far as the number of journal articles, before March 2020, there were 34 relevant articles in the CNKI database, only 8 were journal articles, and most of them were reported by newspapers. However, after a month and a half, the number of related research journal articles had reached 48, and there were 8 research reports published on related websites. So we can see that the number of research about COVID-19 had developed rapidly, and the research quantity and quality had also increased constantly.

As far as the research types, they were more diversified, including research on the specific description of online education, survey reports through questionnaires on the implementation of online teaching, and experimental research on the effects of online teaching.

As far as the research content, the main points were the construction of online teaching environment and resources, and how to carry out teaching guidance. "Cloud classroom", "Network environment", "Live broadcast class", and "Teaching strategy" are high-frequency keywords, which indicate that the teaching platform, resource content, school (teacher) and family-related guidance were the primary concern during the pandemic.

\section{Online Teaching Platform and Resources}

As a new type of teaching method, online teaching provided students with real-time and non-real-time teaching guidance. In this pandemic, national, local or educational informatization companies had provided a variety of platforms and resources, and provided teachers with different possibilities. Therefore, it is one of the research key points.

\section{Classification of Online Platform}

The rich types of online teaching platforms allow teachers to have more choices. Teachers can choose different types of platforms to carry out teaching activities according to their individual teaching needs and preferences.

Yutong Zhao once divided common online teaching platforms into three types in his research: Communication platforms, such as QQ, WeChat, etc.; Document delivery platforms, such as email, Dingtalk, Moodle, Micro-classes, etc; and Webcast platforms, Such as TikTok, Kuaishou, OBS, Zoom, etc. (Zhao, 2017) 
The outbreak of the pandemic has made online teaching more popular. Therefore, the researchers have further subdivided their classification. For example, in a report on interactive research on online education jointly published by the New Media Communication Research Center of Beijing Normal University and Guangming Daily Educational Research Center, 39 online education products that are widely used in the market are divided into the following seven categories:

(i) Social tool: Social software that supports daily communication and corporate office. A variety of teaching functions such as WeChat, QQ, and Dingtalk are realized through the integration of group chats, video and audio conferences, and extension programs.

(ii) Communication tool: With online video conference as the core, it supports simultaneous live teaching, such as Zoom and Xiaoyu link.

(iii) Platform service: Provide a digital teaching environment to assist teachers to complete the entire process of online teaching, and realize functions such as course selection, course scheduling, announcement, online interaction, batch assignments, data management and analysis, such as Seewo and Xueleyun Platform etc.

(iv) Teaching tool: A tool that assists offline or online teaching to realize the digitization and high efficiency of one or several links in teaching, such as 17zuoye.

(v) Public resource: Provide digital public teaching resources such as microclassrooms and teaching materials, the national elementary and middle school network platform and the People's Education TV station.

(vi) Subject content: Subjects' Online learning resources which based on the learning courses, such as Tencent Classroom and People's Open Class.

(vii) Comprehensive tutoring: Online education institutions independently developed online teaching platforms, teaching aids and curriculum systems. It integrates education and scientific research and teaching together, and the institutional teaching team provides students with a comprehensive learning experience, such as Zhibozuoyebang, TAL Education etc.

According to this statistic (teacher's choice of educational products are multiple choices), among these seven types of online teaching platforms, social communication software such as WeChat and QQ, mobile office platforms represented by Dingtalk and National elementary and middle school network platforms, became the first choice for teachers to carry out online teaching. In addition, Zuoyebang, Tencent classrooms, TAL Education, and electronic textbooks from People's Education Press have all become important products for the online teaching (New Media Communication Research Center of Beijing Normal University, Guangming Daily Education Research Center, 2020). The specific analysis statistics are shown in Figure 1:

At the same time, the East China Normal University Curriculum and Teaching Research Institute also investigated the specific use of online teaching platforms by elementary and middle school teachers. According to the questionnaire analysis of elementary and middle school teachers in 23 provinces and cities in the report, 
Dingtalk(56.65\%) and WeChat group (52.75\%) were the primary choices for teachers' online communication and management; As far as live broadcast platforms, more teachers chosed platforms such as Tencent Classroom (36.95\%), Zoom (27.72\%), Tencent Conference (26.01\%), Mooc(13.55\%), CCTalk (8.54\%). (Yang \& Zhang, 2020)

Through the above several research reports, it can be seen that before the "School is Out, but Class is On", online education platforms and related tools had been enriched and expanded. In addition to the country, more education information companies focused on online teaching environment and the development of tools, provided a richer supplement to the online teaching support platform during the pandemic. In addition, teachers had a deeper understanding of the new online teaching technology and functions. In addition to common social tools such as WeChat and QQ, Dingtalk and the National elementary and middle school network platform, Tencent Classroom, etc. had also become the main choice (Figure 1).

\section{Strategy Selection of Online Teaching Platform}

Huang (2020) believed that the choice of online teaching tools should consider the convenience, that is, the tools should help teachers to quickly and easily produce and manage resources, publish notifications and manage students; Help students obtain resources and participate in learning activities quickly and easily; Help teachers and students to communicate conveniently and quickly; Help teachers, parents, and schools to keep updated of students' learning dynamics, and better communications.

From the perspective of overall regional planning, Qing Zhang and others believed that the network platform was the carrier and means of online teaching. Choosing a suitable platform and being able to operate proficiently have a great significant meaning for smoothly developing online teaching. Therefore, it is recommended that each subject in the same grade of each school can only use one platform for online teaching, to avoid switching back and forth during learning, increasing the difficulty of operation, but meanwhile it is allowed one or two assistant platforms for announcement (Zhang \& $\mathrm{Wu}, 2020)$.

More research was focus on how online education was implemented in schools.

For example, Daxiang Dai's research specifically explained how the school used the teaching platforms at all levels to solve the learning needs of different grades during the outbreak (Dai \& Lin, 2020). The article introduced that for the review stage of the first and second year of middle school students, they were required to watch the local TV education channel (Jiangsu Education Channel) and listen to the "Gulou Online Review Course" to conduct home-based independent review. For ninth grade students (the last year of middle school), the school organized students to learn independently by watching the news channels of local TV stations. In the new content teaching stage, on the one hand, the school used the teaching platform like "Jiangling Teachers' Class in the air-Jinling Micro School" in Jiangsu Province, "Pukou Eqixiao" in Pukou District, and the online learning mobile app "Wosu" in Jiangsu to conduct online teaching, on the other hand, use the office communication platform "Dingtalk" to carry out online group live broadcasting, and online interactive teaching through the network live broadcasting 


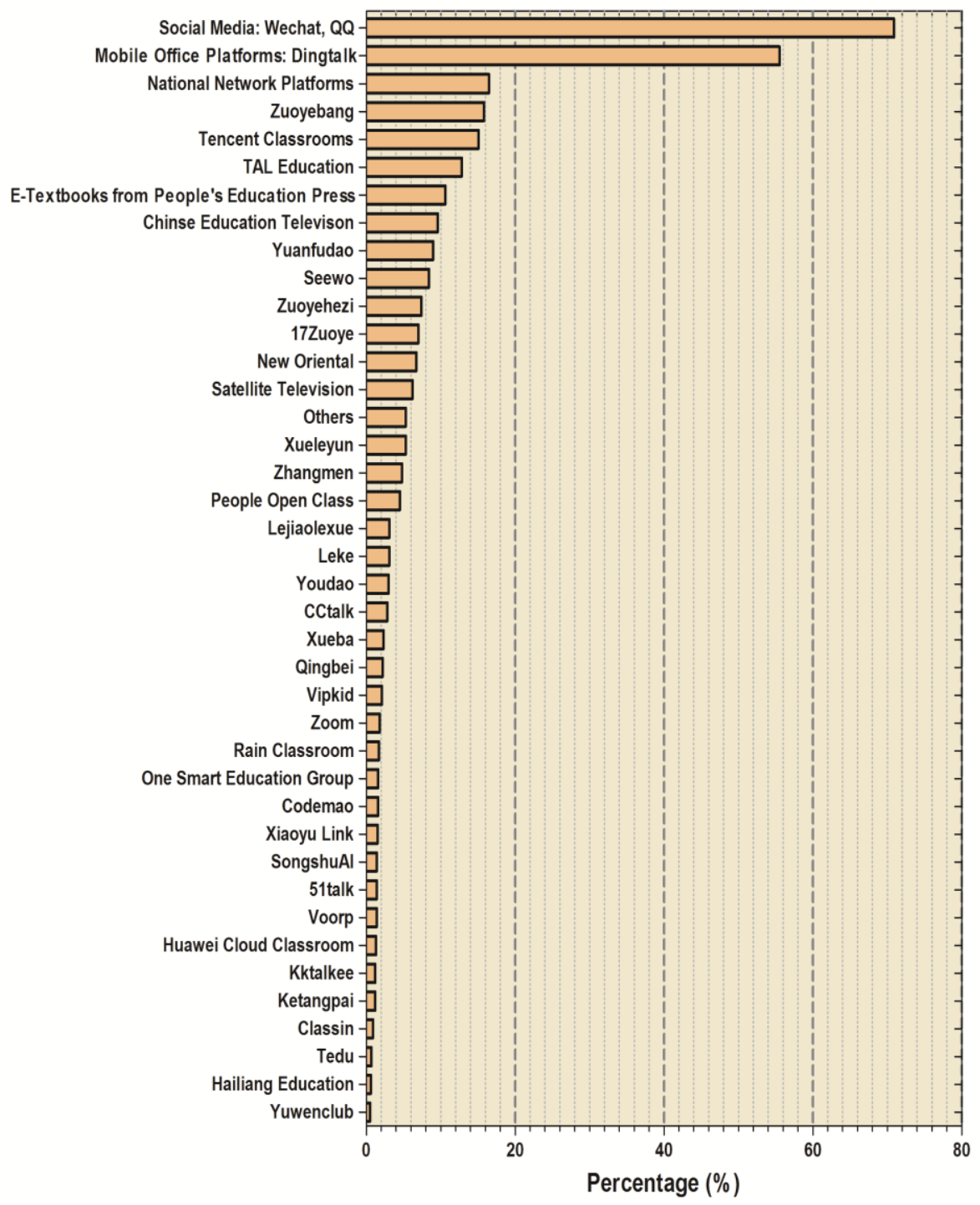

Figure 1. Statistics of Online Learning Platforms in China.

platform. At the same time, the school also used public communication platforms such as QQ or WeChat to establish a communication group for each class, so that teachers can answer and solve questions in a timely manner.

\section{The Construction and Development of Online Resources}


The quality of teaching resources has an important influence on the effect of online teaching. Therefore, in addition to online teaching platforms, the development and integration of online teaching resources had also attracted the attention of researchers.

The construction of online teaching resources was not an overnight effort. Some scholars had done research on the basis of online teaching resources in China this time. According to the data of the Ministry of Education's Cyber Security and Informatization Leading Group in 2020 quoted by Longjun Zhou, as of 2019, the national system has launched a comprehensive collection of high-quality basic education resources for the entire society, bringing 290 units together and a total of 457 teaching applications. Through the activity of "One Teacher One Excellent Class, One Excellent Teacher One Class", it attracted more than 2.28 million teachers to participate, collected 3.14 million online courses, recommended 17,312 provincial excellent courses, and selected 1,005 ministerial excellent courses, and generated 8 million resources. Therefore, the article claimed that the achievements of the construction of digital teaching resources from the beginning of this century have provided strong resource support for the large-scale online teaching activities during the pandemic (Zhou, et al, 2020).

Researchers have also seen that during the pandemic, the large-scale online teaching has benefited from the interaction of various parties in the society. In order to provide rich online teaching resources, the state, local governments and enterprises had made efforts.

As reported in the 11th edition of the People's Daily on February 3, the Chinese government has, since February 17, opened the national elementary and middle school network cloud platform and online courses for free to students from elementary to high school.

On the other hand, China Education Television provided to nationwide elementary students, 8th and 12th grade students with free "New Education Elementary School Edition Textbook Synchronization Class", "Mathematics, Physics, Chemistry courses". At the same time, for some rural areas and remote poverty-stricken areas where there is no Internet or slow Internet speed, courses and resources will be broadcast through TV channels to ensure that the essence and effect of online and offline teaching are the same (Zhao, 2020).

In addition, local governments have also organized teaching and research teams to study teaching methods and learning resources suitable for the region. For example, Tianjin Municipality organized kindergarten teachers and researchers in response to the needs of young children's family education, based on "Guidelines to Learning and Development for Children Aged 3-6"; they recorded 10 video games for young children (Tianjin Education Commission, 2020). For the 8th and 12th grading student, Fujian Province organized teaching and research teams to develop suitable teaching methods and learning resources, and sent the course content to students as "curriculum" to ensure that those students can successfully pass the End of Grade test (Fujian Education Department, 2020).

In addition to national and local governments, educational information-based enterprises such as Bytedance, Yuanfudao, Zhibozuoyebang, VipKid and other compa- 
nies provided free online live teaching systems to all elementary and middle students. The provision of a large number of high-quality online teaching resources provided a solid foundation for this large-scale online teaching activity (Zhao, 2020).

\section{The Selection Strategy of Online Teaching Resources}

High-quality and rich learning resources were not equivalent to effective learning. They need to be closely related to the teaching object and content, and match the physical and mental characteristics of the learner. Therefore, how to choose appropriate online teaching resources was also one of the major focuses.

Regarding how to select appropriate online teaching resources, Huang et al. (2020) believed that the following points should be considered:

(i) Appropriate content, that is, the learning resources must be highly related to the learning object and content and can arise the interest of the students, or they are necessary to solve the problems;

(ii) Appropriate difficulty, that is, the content is moderate in difficulty and moderate in size, and will not make students overloaded;

(iii) Appropriate structure, that is, the structure of the learning content is clear and the organization is reasonable, and it will not make students confused;

(iv) Appropriate media, the presentation form of the media is easily accepted by students to prevent visual fatigue, especially for young students;

(v) Proper resource organization. That is to effectively organize the selected learning resources (such as video, animation, text, electronic textbooks, virtual reality, etc.) to ensure that the navigation layout is clear and the depth is moderate, and the students will not lose their way.

In the specific implementation process, different schools have integrated and enriched online resources according to their own conditions. For example, the Zhenjiang Experimental School in Jiangsu Province digitized the textbook guidance materials to form a digital guidance draft, which provided more targeted teaching materials (Xia, 2020); The No. 2 Daxie Elementary School in Ningbo, Zhejiang Province organized each teacher to design a guidance program (task list) based on the learning objects and the students' learning situation, which made the knowledge organized and systematic (Xie \& Yang, 2020); The Second Experimental Middle School of Henan Province independently developed online curriculum resources during the pandemic. The 164 online courses not only enriched online learning resources, but also allowed the 12th grade students to further adapt to online learning (Zhou, 2020).

\section{The Organization and Implementation of Online Teaching}

Teachers, students and parents are the main participants in education. Under the impact of the pandemic, normal classroom teaching could not be carried out, and it shifted from offline to online. The change of learning methods, the assistance and cooperation 
of parents are important guarantees for online teaching. Therefore, how to organize and implement online teaching has become a topic

\section{Online Teaching Methods}

The form of teaching organization is a link between teachers and students, and it is a way to organize teaching activities according to certain teaching ideas, purposes, content, and subjective and objective of teaching conditions. The emergence of online teaching in the pandemic relies on the strength of teachers, demonstrating their practical ability and real level.

\section{Implementation Overview of Online Teaching}

At the beginning of this large-scale online teaching development, the teaching and research of Education department of the Zhejiang Province organized all provincial teaching and research departments to carry out a survey on the online learning of middle and ordinary high school students in the province. The results showed that $96.0 \%$ of the students who have participated or are participating in online teaching activities organized by the school, while only $4.0 \%$ have not participated. This showed that online teaching has become the main method of education and teaching for the middle and high school during the pandemic in Zhejiang Province (The Education Department of Zhejiang Province, 2020).

Later, a survey report issued by the Academy of Educational Sciences of $\mathrm{Hu}-$ nan Province involving 31 provinces, cites, autonomous regions and Hong Kong, Macao and Taiwan regions also responded. In this report, $79.34 \%$ of the research objects had already conducted online teaching, urban area is $83.41 \%$ and urban area is $77.42 \%$. It was concluded that online teaching had become very norm in China during the pandemic. About $80 \%$ of schools in Hunan Province, whether it is urban or rural, had launched online teaching, and teachers had tried every method to teach students. Teaching methods was also diverse. The data showed that $36.48 \%$ of the schools were mainly relied on "learning public teaching resources", $31.56 \%$ were "teacher recording or using existing resources", 11.6\% were "teacher live teaching" (Academy of Educational Sciences of Hunan Province, 2020).

\section{Classification of Online Teaching Organizations}

Some scholars believed that the organizational form of online teaching should follow the idea of "flexible teaching". Each element in teaching does not stick to the inherent model, and makes corresponding adjustments according to the actual situation, to be able to learn easily, devotedly and effectively (Ma \& Du, 2002). Some scholars summarized the online teaching mode of this period. For example, Zhiting Zhu and Hongchao Peng (2020) had proposed three application modes - Direct teaching, Self-learning, and Flip learning; Jianli Jiao and Xiaoqing Zhou (2020) had summarized several typical solutions - Online courses, Online live broadcast teaching, Student self-learning, and Television air classroom, etc ; Dongdong Wang et al. (2020) proposed four common 
online teaching and service models based on platform selection: "TV teaching video", "Live classroom", "Resource class communication" and "Self-selected resources + Online Q \& A".

\section{Selection Strategies of Online Teaching Organization}

Regarding the selection of teaching organization methods, some scholars pointed out: "Schools should allow teachers to flexibly choose suitable teaching organization forms for different learning contents according to the teaching resources and local network facility (Huang, 2020) . For example, the First Middle School in Changyuan City, Henan Province, through a guided learning program, launched online teaching activities, combined with students 'independent learning methods, created a six-step teaching method (Cai \& Wang, 2020); The Experimental Elementary School of Xiamen did not blindly follow the advanced educational products at the beginning of online teaching, but required all teachers and students to use QQ groups as an platform to ensure that them can be smoothly involved in a short time. After a stable period, the school encouraged everyone to try other systems such as the National Education Digital Resource Network to ensure that online education activities can be carried out more efficiently and stably (Liu, 2020).

The combination of reality, innovation, and development of distinctive teaching organizations guaranteed the quality of online teaching.

\section{Online Learning Methods}

Learning methods refer to all learning methods and forms adopted by learners in various learning situations with different motivational orientations, mental processing levels and learning effects. It includes not only the learning methods and strategies that focus on the individual level of students, but also the learning methods of teachers and students (Pang, 2010). Affected by the pandemic, classroom teaching could not be carried out under normal circumstances, the learning environment had changed, and the learning methods had also been changed. Therefore, how to divide learning methods, which learning methods are mainly adopted by students, and how to let students to choose different learning methods according to their learning characteristics had become a topic.

Some scholars believed that different learning methods are suitable for different scenarios and students, and the tools they rely on are also different. Based on this, the online learning methods during the pandemic are divided. For example, Huang (2020) believed that the choice of learning methods should considered the characteristics of the learner, the level of cognitive processing, learning participation and etc.

Based on this, relevant education departments represented by Beijing city had advocated teachers screened learning resources and guided learning content according to the learning characteristics of their students. Teachers should strengthen offline guidance to students, and especially use this opportunity to guide students to try offline selflearning (Shi, 2020).

\section{Parents Cooperating with Online Teaching}


Family and school co-education is to cultivate students through family education and school education, to promote the overall development and healthy growth of students. During the postpone school period, the family has become the only place for students to learn, and parents have become an important partner in student learning. Communication and cooperation between school and family is an important measure to promote "School is Out, but Class is On" (Cheng, 2020). Therefore, parents' knowledge of online teaching and how to strengthen cooperation had become one of the research topics.

\section{Parents' Knowledge of Online Teaching}

The Department of Education of Heilongjiang Province conducted a questionnaire survey on the satisfaction with online teaching of parents across the province. According to the report, up to $39.84 \%$ were very satisfied, $19.71 \%$ were less satisfied, $38.01 \%$ were relatively satisfied, and only $2.44 \%$ of were not satisfied (Figure 2). $92.33 \%$ of parents felt that "schools and teachers actively contacted them and communicated the cautions and arrangements for online learning." They were very satisfied with it (Heilongjiang Provincial Department of Education, 2020).

In Wang's (2020) report, we can see that parents have another attitude towards online education: on the one hand, $49.2 \%$ of parents were expecting the school to take remedies for online teaching, but on the other hand, some parents worries for various reasons, such as the choice of online courses $64.1 \%$, unfamiliar network operation $52.4 \%$, insufficient network and equipment conditions $14.7 \%$, affected vision $59.9 \%$, concertation $57.3 \%$, online temptation $49.2 \%$, unanswered questions $43.9 \%$, and poor learning effectiveness $40.9 \%$ have all become concerns for parents.

\section{Measures for Home and School Cooperation}

In order to better manage home learning, the school organized room-teacher to establish a class communication management platform. Through multiple channels such as class QQ group, WeChat group or school platform, school official WeChat, etc., the school had established a positive, smooth and effective communication to maximize the support and cooperation of parents. And through the communication platform, the school can statistics and monitor the students' online viewing of online courses and homework submissions to better control the students' home learning (Cheng, 2020). For example, Jiangsu Zhenjiang Experimental School built a platform for online learning and a homeschool co-education network platform through the province, city and school platforms. In addition, it also realized remote interaction with parents through the public communication platform QQ and WeChat group. At the same time, the school replied on the Education Bureau of the Province and Cities to develop online learning resources to deeply dig out parent resources, and enrich home learning resources. In addition, in order to better achieve home-school co-education, the school had specific requirements for teachers and parents to ensure the quality of online learning (Xia, 2020). 


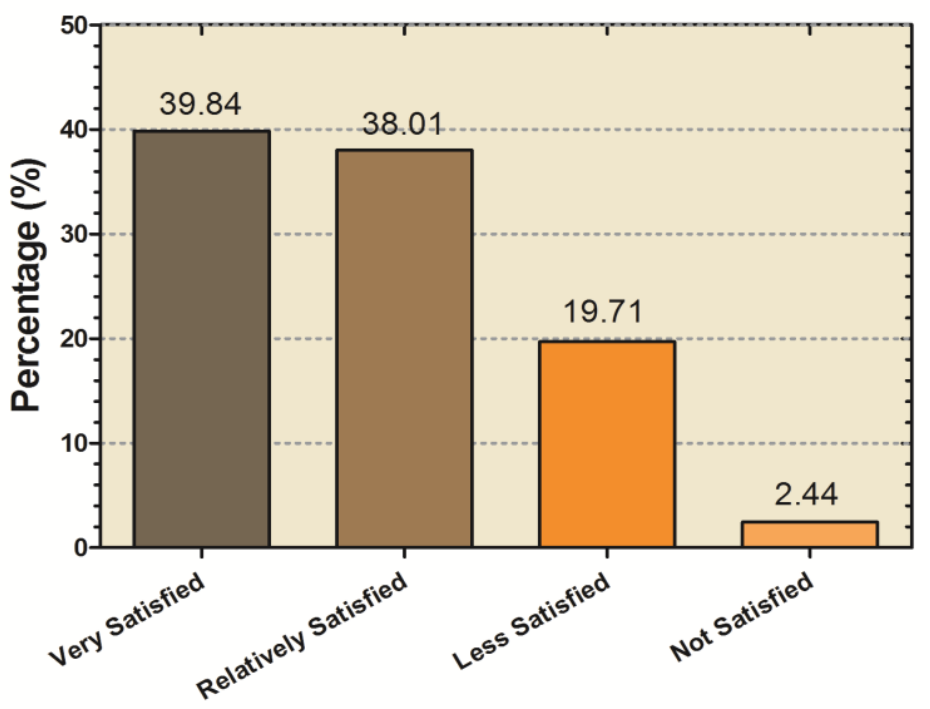

Figure 2. Satisfaction of Online Learning.

\section{The Achievements and Deficiencies of Online Teach- ing Implementation}

With the pandemic situation getting better in China, education will gradually return to normal. As of April 20, 26 provinces in China have started back to school (Wang \& Wang, 2020), and the implementation of "School is close, but Class is On" will also come to an end. How effective it is and what are the deficiencies have become concerns.

\section{The Effectiveness of Online Teaching}

Launching online teaching nationwide is the first attempt in Chinese education history. Compared with traditional teaching methods, can online teaching bring new enlightenment to students in a home learning environment? Which teaching method can improve teaching efficiency? Can online teaching better promote individualized teaching and the balance of quality education? The effectiveness of online teaching has attracted the researchers' attention.

For example, Yao used evidence-based research method to study 1,024 samples from No. 8 Guiyang Middle School and another school with the same educational conditions and students. They analyzed the impact of two online teaching methods, recording and broadcasting, and live broadcasting, on student performance, and concluded 
that more get involved by teachers is an effective way to improve teaching efficiency. (Yao et al, 2020)

Hui et al. (2020) also conducted research on the effect of technology on online teaching, and concluded that the accurate support of big data reduces the student's academic burden, guarantees the normal development of teaching, and improves teaching efficiency.

Although the research on this part is not sufficient at present, as the normal teaching gradually recovered, the research on the effectiveness of online teaching will also be continuously supplemented and enriched.

\section{The Problems Existing in Online Teaching}

Since the implementation of "School is Out, but Class is On" in China, large-scale online teaching had replaced the normal classroom teaching, and various regions had also taken actions to respond to this change, ensuring the continuity of learning. However, some scholars had seen that in the specific implementation process, the implementation of large-scale online education had been affected by infrastructure construction, unadoptable teaching methods, and unequal information literacy of the participants.

\section{The Infrastructure in A Few Areas is Weak that Affects the Implemen- tation Effect}

Compared with developed regions, underdeveloped regions still have some problems in terms of home learning terminals and the coverage, availability and stability of network conditions. Some scholars said that it is the first time in China's basic education that large-scale online teaching replaced normal school teaching. The infrastructure preparation for large-scale online education is insufficient, and large-scale concurrent accesses greatly exceeds the platform's regular service capabilities, online teaching Platforms (such as Cloud classrooms, Rain classrooms, and Dangding Dong) were usually overwhelmed (Zhang et al, 2020), and problems such as stuck and frequent offline seriously affected the learning experience ( $\mathrm{Li}, 2020)$. In the later period, the power of the national social enterprise had greatly improved the network operation ability, and online teaching support environment had been improved.

\section{The Lack of Scientific Property and Applicability of Some Teaching Plan Affected the Teaching Effect}

Teaching plan should be designed and implemented according to the actual situation of the school to ensure the pertinence and scientific property of teaching. However, in terms of specific implementation, some schools had a relatively simple practice model, especially in the early days of online teaching. They used the same teaching method as offline teaching, or the same time schedule as the original, without comprehensive consideration, evaluation and design of the teaching content of different levels and different disciplines. 
According to the questionnaire survey of the Education Research Office of the Department of Education of Zhejiang Province, there are 7 online learning methods (Live broadcast, Recording, Resource pack, Live broadcast + Recording, Live broadcast + Resource pack, Recording + Resource pack, Live broadcasting + Recording + Resource package), Pure Live broadcast got the highest proportion, reaching $51.8 \%$, but in a survey of student satisfaction, the Resource package (the teacher does not teach, just provides learning resources for students to learn by themselves) was the learning method with the highest student satisfaction. In addition, the questionnaire also counted the way students submit their homework, the number of daily courses, and the time of each course. From the survey, problems such as long class hours and study time, electronic homework, and online punch-in were still highlighted (The Research Office of the Department of Education of Zhejiang Province, 2020). In this regard, the report recommend that schools arrange and adjust online learning from the perspective of improving the physical and mental health of students, and design teaching programs that meet the actual situation. In addition, Wang also emphasized that during the implementation of online teaching, encourage "One school One Teaching Plan", "One class One teaching plan", "One teacher One Teaching Plan" (Wang et al, 2020).

\section{Inadequate Literacy of Some Subjects}

The lack of information literacy was another practical problem faced by this large-scale online teaching implementation. Some scholars said that many teachers, students and parents were unable to follow the online teaching. In the absence of relevant guidance from the school, the participants showed inordinate "out of control" and "anxiety" during the implementation process (Jiao et al, 2020). More scholars have analyzed from the survey report that there may be problems in the information literacy of the subjects.

\section{Teachers' Online Teaching Abilities are Different}

According to the relevant research report of the Institute of Curriculum and Teaching of East China Normal University, most teachers have self-study experience with online platforms (45.22\% are frequently used and $37.69 \%$ are occasionally used). And most teachers are not stranger to online education (40.29\% knew very well and $45.50 \%$ knew better). However, for large-scale teaching using online platforms, $41.26 \%$ of teachers still found it difficult, even $21.80 \%$ considered very difficult (Yang \& \& Zhang, 2020). In the relevant survey report of Beijing Normal University (Wang, et al, 2020), this situation had also been verified, and $42 \%$ of teachers were anxious about carrying out large-scale online education. The main reason does not know how to interact with students online, how to organize teaching activities, and how to deal with equipment operations. Teachers also generally are lack of online teaching experience and cannot quickly adapt to and exert the advantages of network technology.

\section{The Lack of Online Self-Learning Ability of Students and Difficult to Guarantee the Participation of Learning}


In the questionnaire survey of 9,824 parents of elementary students in 9 counties in Sichuan Province by $\mathrm{Pu}$ et al (2020), parent thought that children were not concentrate $(44.48 \%)$ and irregular learning time $(44.06 \%)$ are the main problems of online education. The results showed that $38.54 \%$ of the students had insufficient confidence in adapting online learning quickly; $37.1 \%$ believed that they had poor initiative in online learning, and $45.79 \%$ considered that need the supervision of teachers and parents to complete the task of online learning. As a result, students' independent learning ability had become an important factor that affects the final results of online learning.

\section{Insufficient Parents' Ability to Assist Children in Online Learning}

Parental assistance is of great significance to online learning. According to a survey of elementary and middle school teachers, students, parents, and educational institutions in seven major regions including East, Central, and South China conducted by the Zhongguancun Internet Education Innovation and the Collaborative Innovation Center established by the Ministry of Education and the Balanced Development of Informatization and Basic Education in China, during the pandemic, 23.4\% and 29.6\% of the parents indicated that they have been or often accompanied their children for online learning, and 38.1\% just occasionally, but 7.9\% were not (Wang \& Fu, 2020).

According to the survey results of Jiang et al. (2020), 52.4\% of parents reported that they were not familiar with the operation of online learning, and there were no active and effective solutions to the problems that may occur in online learning.

Based on this, Xie suggested that in addition to strengthening technical guidance and design theory guidance for teachers' online teaching, schools should also pay attention to relevant guidance for students and parents. This can train students to learn and manage independently, and establish a good home-school collaboration mechanism. Under the premise of respecting different school periods, different grades, different students' cognition laws and home learning laws, according to the unevenness of parents' education, experience, and ability, so as to ensure the implementation of online teaching (Xie et al. 2020).

\section{Perspective}

In this large-scale online teaching activity, the transformation of educational space forced the participants of various educations to quickly adjust and adapt to changes. This is not only a new problem that schools, families and students have ever encountered, but also an important challenge facing China's basic education.

It can be seen from the currently published studies that the content of online education research during the pandemic mainly focused on the following aspects.

(i) The rich education platform and resources are the strong support for this online teaching. Based on this study, we can see that under the state of suspension of classes across China, the Chinese government has combined various forces to provide a diverse teaching platform and rich teaching resources for online teaching, which has better supported the distance learn- 
ing of students across the country. This ensures the continuity and scientific property of education and teaching in an extraordinary environment, thereby promoting the healthy development of students' physical and mental health at home.

(ii) Teaching guidance and home-school cooperation are the guarantee of online teaching. At the same time, we also noticed that how to make education technology and teaching more deeply integrated to better serve education and teaching, and then ensure the continuity of education in the abnormal environment has become the main problem of teaching. Therefore, changes in the teaching environment have changed both teaching methods and learning methods. Appropriate guidance from teachers and autonomous learning of students has become a new model under the implementation of online teaching. At the same time, parental assistance and joint participation ensure online teaching.

(iii) Exerting effectiveness is fundamental to online teaching. After a period of implementation, we found that online teaching at this stage has achieved some results. The integration of educational technology and teaching makes the teaching more personalized, and the teacher's online guidance makes online teaching more adaptable to students' learning needs. Although there is not much research on this aspect at present, we believe that with the continuous resumption of classes across the country, online teaching will enter the stage of convergence with classroom teaching, and research on its effectiveness will be supplemented and enriched.

However, it should be pointed out that there are also limitations in the implementation of large-scale online teaching in the outbreak, such as: the infrastructure in a few areas is relatively weak; the teaching methods or contents are not suitable; and the level of informatization of some education participants was inferior.

Existing research has certain limitations in terms of both research methods and research content.

(i) Insufficient evidence-based research in education. From the perspective of research methods, the existing research is more qualitative research, and the evidence-based research in education is slightly insufficient. It can be seen from the literature that educational surveys and educational experimental research account for less than $25 \%$, which makes the research evidence insufficient.

(ii) Too much bias towards educational technology. From the literature, most of them were biased to educational technology, but less substantial discussion of the implementation and operation of online education during the pandemic.

These questions are also forcing us to keep thinking: how do we design toplevel education for similar public health emergencies? How can schools respond quickly and comprehensively? How to formulate an adaptation plan based on actual needs? 
How to provide more professional guidance to teachers, students and families? These will become important issues for education after the epidemic.

How to Cite: Zhou, L., Li, F. (2020) A review of the largest online teaching in china for elementary and middle school students during the COVID-19 pandemic. Best Evid Chin Edu, 5(1):549-567. Doi: 10.15354/bece.20.re040.

\section{References}

Cai, R.C., Wang, Q.Z. (2020) A six-step online teaching method based on protocol-guided learning during the COVID-19 epidemic: A case study of the first middle school teaching practice in Changyuan city, Henan province, China. Best Evid Chin Edu, 4(2):529-534.

Chen, L., Wang, Z., Li, F., Jiang, Y., Chen, Y. (2012) Research on creating public sharing model for digital learning resources. Chin Audiovi Edu, (01): 73-77.

Cheng, X.Q. (2020) Challenges of "School's Out, But Class's On" to school education: practical exploration of Chinese schools during the COVID-19 pandemic. Sci Insigt Edu Front, 5(2):501-516.

Dai, D.X., Lin, G.F. (2020) online home study plan for postponed 2020 spring semester during the COVID-19 epidemic: A case study of Tangquan Middle School in Nanjing, Jiangsu province, China. Best Evid Chin Edu, 4(2):543-547.

Department of Education of Fujian Province. Fujian Province has done a good job in the prevention and control of new coronary pneumonia [EB/OL]. (2020-02-14) Available at: Http://www.moe.gov.cn/jyb_xwfb/s6192/ s222/moe_1745/202002/t20200214_4210 16.html.
Department of Education of Heilongjiang

Province. (2020) Big data analysis of 1.28 million questionnaires to explain the online teaching management of our province's basic education during the epidemic. 04-04-2020. Available at:

Https://mp.weixin.qq.com/s/ H6pxXH6pLc0uOqdUsJ9RIA.

Ding, Y., Yu, B. (2020) Suspension of nonstop classes, enriching the rich curriculum-teachers and students work together to "air classroom". People's Daily, 03-012020. Available at:

http://www.moe.gov.cn/jyb_xwfb/s6192/s 222/moe_1733/202002/t20200213_42069 4.html.

Huang, R., Chen, G., Zhang, J., Chen, P., Li, S. (2010) Five laws on technology promoting learning. Open Edu Res, 16(1):1119.

Huang, R., Zhang, M., Shen, Y., Tian, Y. \& Zeng, H. (2020) Research on the core elements of an ultra-large-scale Internet education organization: Case analysis of online education effectively supporting "School is Out, but Class is On". Res Audiovis Edu, 41(3):10-19.

Hunan Academy of Educational Sciences. (2020) Online education and teaching questionnaire for elementary and middle schools during the new coronary pneu- 
Zhou \& Li. A Review of the Largest Online Teaching in China during the COVID-19.

monia epidemic. Available at:

Https://baijiahao.baidu.com/s?id=166058

$4819292069530 \& w f r=$ spider $\&$ for $=p c, 03-$ 08-2020.

Jiang, H., Jiang, L., Yu, R. (2020) The construction of an online interactive teaching model during the school postponed of COVID-19 pandemic. Chin Audiovis Edu, (04):40-41.

Jiao, J., Zhou, X., et al. (2020) Case Study on online teaching of "School is Out, but Class is On s" during of COVID-19 pandemic. Chin Audiovis Edu, (3):106-113.

Kong, Q. (2020) Practical exploration of home study guidance for students during the COVID-19 Pandemic: A case study of Hangzhou Liuxia elementary school in Zhejiang Province, China. Sci Insigt Edu Front, 5(2):557-561.

Lanzhou Educational Science Institute. (2020) "Statistical Report on the Investigation of the State of Home Study During the New COVID-19 pandemic among elementary and middle school students in Lanzhou".

Liu, L. (2020) Where is the future education going? The world's largest "educational experiment" will promote the "revolution" of the learning model in elementary and middle schools. People's Political Consultative Conference, 03-23-2020.

Liu, S. (2020) How to organize normal online learning under the pandemic. Chin Audiovis Edu, (04):35-36

Ma, X., Du, L. (2002) The evolution of teaching organization and network teaching. Edu Res, (4):49-51.

Ministry of Education Network Security and Informationization Leading Group of The People's Republic of China. (2020) Summary of education informatization and cyber security in 2019, 03-04-2020.

Ministry of Education of the People's Republic of China. (2020) Online teaching organization and management in universities during epidemic prevention and control. Available at:

Http://www.moe.gov.cn/jyb_xwfb/xw_xt/ moe_357/jyzt2020n/2020_zt03/zydt/zydt_ jyb/202002/20200205_418131.html, 0205-2020.
New Media Communication Research Center of Beijing Normal University and Guangming Daily Education Research Center. Online education interactive research report of elementary and middle schools during the new COVID-19 Padamic. 04-02-2020. Available at: Https://share.gmw.cn/edu/2020-04 /02/content_33708443.htm?s=gmwreco2.

Pang, W. (2010) On Learning Methods. Cours Teach Mat Teach Method, 30(5):13-19.

Shi, J. (2020) Refuse "Online full irrigation" and guide students to learn independently offline. Chin Edu News.

Teaching and Research Section of Department of Education of Zhejiang Provincial Department. (2020) Investigation and research on online teaching in middle schools during the pandemic situation in Zhejiang Province. Digit Teach Element Middle Sch, (03):66-69.

Tianjin Municipal Education Commission. (2020) Tianjin does its best to prevent and control pandemic situation and protect the health of teachers and students.

UNESCO Institute for Statistics, (2020) COVID-19 Educational Disruption and Response, Available at: https://en.unesco.org/covid19/educationre sponse, 04-20-2020.

Wang, D., Wang, H., Zhang, W. (2020) Research on online teaching during the pandemic of "School is Out, but Class is On": Based on a nationwide survey of 33240 online questionnaires. Modern Edu Tech, 30(3):12-18.

Wang, J., Fu, W. (2020) Portrait of big data for online education in elementary and middle schools under the pandemic situation. China Youth Daily, 04-13-2020 (8 Edition).

Wang, Y., Wang, N. (2020) Hubei college entrance examination and school start time announced, the latest national school start situation is coming. People's Daily, 04-20-2020.

Wang, Z., Wu, Y., Liu, SY. (2020) Online learning promotes teaching model reform. Chin Edu News, 02-22-2020.

World Health Organization. (2020) Coronavirus disease 2019 (COVID-19) Situation 
Zhou \& Li. A Review of the Largest Online Teaching in China during the COVID-19.

Report -90. Available at:

Https://www.who.int/docs/defaultsource/coronaviruse/situation-

reports/20200419-sitrep-90-covid19.pdf?Sfvrsn $=551 \mathrm{~d} 47 \mathrm{fd} \_2,04-20-2020$

Xia, J.P. (2020) Practical exploration of school-family cooperative education during the COVID-19 epidemic: A case study of Zhenjiang Experimental School in Jiangsu province, China. Best Evid Chin Edu, 4(2):521-528.

Xia, J.P. (2020) Teaching for student learning: Exploration of teaching strategies based on protocol-guided learning. Sci Insigt Edu Front, 5(1):451-467.

Xie, Y., Qiu, Y. Huang Y. (2020) The characteristics, problems and innovations of the online teaching method of "suspending classes without stopping classes" during pandemic prevention and control. Audiovis Edu Res, 41(3):20-28.

Xie, Z.D., Yang, J.N. (2020) Autonomous learning of elementary students at home during the COVID-19 Epidemic: A case study of the Second Elementary School in Daxie, Ningbo, Zhejiang province, China. Best Evid Chin Edu, 4(2):535-541.

Yang, X. Zhang, Y. (2020) Analysis of online teaching and online training of elementary and middle school teachers under pandemic prevention and control. Modern Edu Tech, 30(3):5-11.
Zhang C., Tang Q. (2020) Apocalypse of the "Great Examination": The fifth report of the series of "Suspended and Non-stopped Education" in the education system to fight the epidemic situation. Chin Edu News, 03-28-2020.

Zhang, Q., Wu, X. (2020) Suspension of classes and non-stop school Qingyang in action: Research on online teaching during pandemic prevention and control in Qingyang District, Chengdu. Chin Modern Edu Equip, (2):4-6.

Zhang, W., Wang, Y., Yang, L., et al. (2020) Suspending classes without stopping learning: China's education emergency management policy in the COVID-19 Outbreak. J Risk Financ Manag, 55(13):26.

Zhao, N. (2020) The start of school will be postponed, and the teaching will not be postponed. People's Daily, 02-03-2020.

Zhou, B. (2020) Practical observation and rational thinking on the public welfare supply of online course resources under the background of COVID-19. Digit Edu, (01): 9-14.

Zhu, Z., Peng, H. (2020) All-media learning ecology: A practical solution to the problem of going to school during a largescale pandemic. Chin Audiovis Edu, (03):1-6. 